Research Article

\title{
Optimization of Subsurface Smart Irrigation System for Sandy Soils of Arid Climate
}

\author{
Qazi U. Farooq ${ }^{D},{ }^{1}$ Muhammad T. Naqash ${ }^{(D)}{ }^{1}$ Abdelkader T. Ahmed ${ }^{D},{ }^{1}$ \\ and Bilal A. Khawaja $\oplus^{2}$ \\ ${ }^{1}$ Department of Civil Engineering, Islamic University of Madinah, Saudi Arabia \\ ${ }^{2}$ Department of Electrical Engineering, Islamic University of Madinah, Saudi Arabia \\ Correspondence should be addressed to Qazi U. Farooq; qaziumar@gmail.com
}

Received 8 September 2021; Revised 2 November 2021; Accepted 16 November 2021; Published 14 December 2021

Academic Editor: Houari Ameur

Copyright (c) 2021 Qazi U. Farooq et al. This is an open access article distributed under the Creative Commons Attribution License, which permits unrestricted use, distribution, and reproduction in any medium, provided the original work is properly cited.

\begin{abstract}
The Arabian Peninsula is an arid zone with a hot desert climate and severe water scarcity. The low humidity, elevated ambient temperatures, and high evaporation rates in the region deemed conventional surface irrigation unsustainable. The IoT-based subsurface smart irrigation systems can be essentially developed for these regions to avoid surface evaporation losses. In this research, the sandy soil conditions of western Saudi Arabia have been considered in numerical simulations to evaluate the performance of a subsurface smart irrigation system. The influence zone of saturation generated by subsurface diffusers in the target root region has been analysed for two different types of sandy soils. The simulation results generated by the COMSOL Multiphysics program reveal that the subsurface smart irrigation system can be effectively applied to simultaneously manage the target root zone at the ideal saturated conditions and prevent surface evaporation losses.
\end{abstract}

\section{Introduction}

The Arabian Peninsula is one of the world's largest peninsulas. The region lies on an arid to extremely arid subtropical climatic belt [1]. The precipitation in the region is scarce, with extremely dry summer and scattered showers in winter [2]. The kingdom of Saudi Arabia is the largest country in the region and was chosen as the focus area for the study. The country has a mostly desert climate. Historically, the population of the area concentrates around oasis and spring regions with the possibility of irrigated agriculture [3]. As per 2018 statistics, agriculture accounts for only $2.8 \%$ of the country's GDP [4]. Naturally, desert regions have very low availability of biological water [5], and most of the agricultural activities are irrigation dependent. The agriculture sector consumes the largest amount of water (about 88\%) in the country by means of irrigation [6]. The country has minimal overall precipitation and lacks permanent rivers and freshwater lakes; therefore, the main reliability of irriga- tion is on groundwater. It is estimated that up to $85 \%$ of the water supply came from groundwater sources which are rapidly depleting [7]. The Saq aquifer is one the largest groundwater sources in Saudi Arabia; the analysis of the aquifer done by using gravity recovery and climate experiment (GRACE) shows an alarming depletion rate of more than $2 \mathrm{~km}^{3} /$ year [8]. To establish the recharge facility, the country has built more than three hundred dams to store the surface runoff; about $90 \%$ of these dams are used for groundwater recharge [9].

Due to water scarcity and the harsh environment in the region, the center pivot sprinkler irrigation system is preferred over traditional open surface water cannel irrigation methods $[10,11]$. Yet, the method is relatively inefficient in water conservation and has huge evaporation losses in the dry climate.

Smart irrigation is currently gaining popularity where digital tools are utilized to control the agricultural water requirements. The efficiency of these methods depends on the real-time and accurate analysis of ground conditions. 


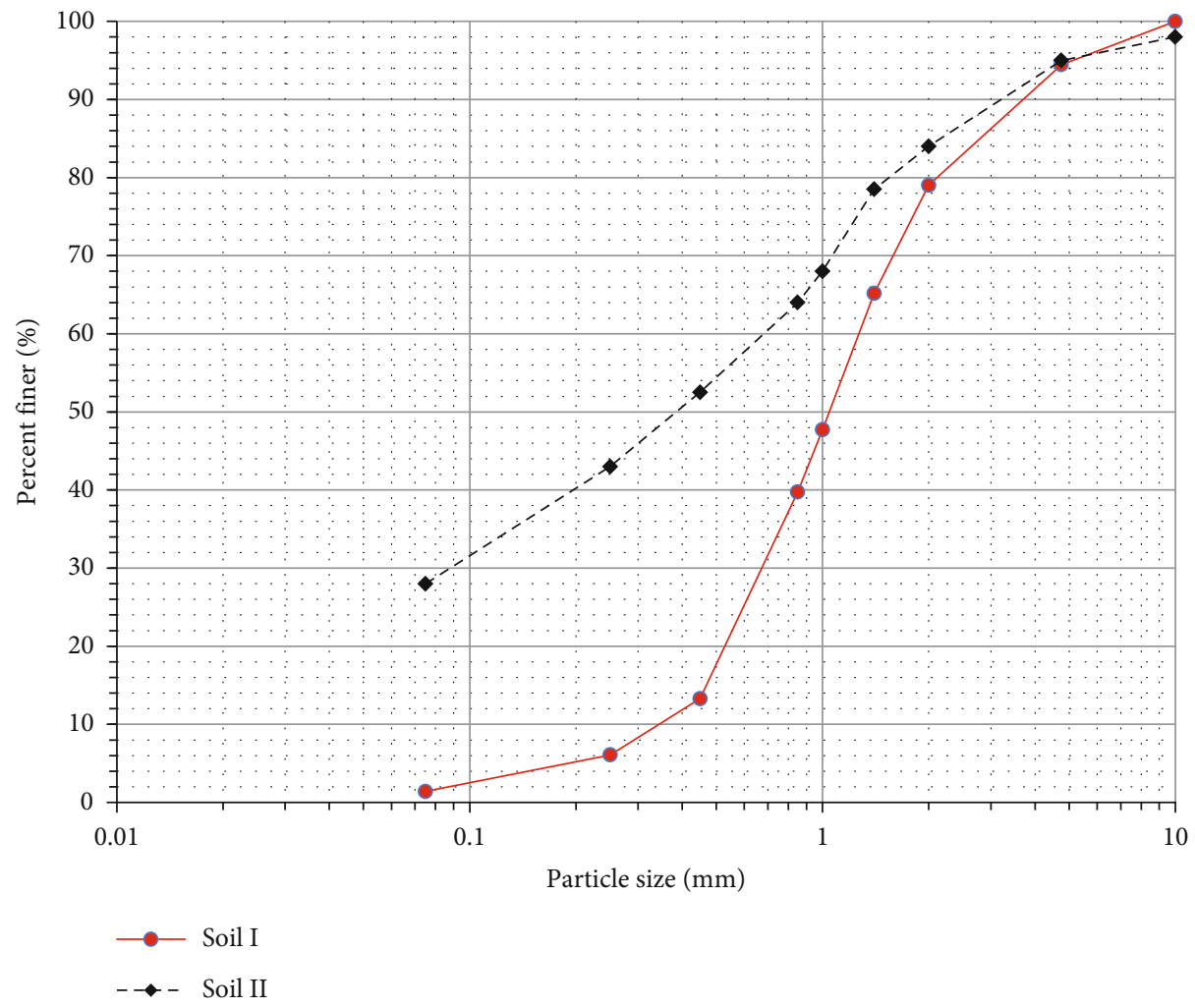

Figure 1: Particle size distribution curves for considered soils.

TABLE 1: Hydrological properties of sands and study cases.

\begin{tabular}{|c|c|c|c|c|c|c|c|}
\hline Soil type & USCS (USDA) classification & Sand content (\%) & $D_{50}(\mathrm{~mm})$ & $\begin{array}{l}\text { Density, } \\
\rho\left(\mathrm{kg} / \mathrm{m}^{3}\right)\end{array}$ & $\begin{array}{l}\text { Porosity, } \\
n(\%)\end{array}$ & $\begin{array}{l}\text { Hydraulic conductivity, } \\
\qquad k(\mathrm{~m} / \mathrm{s})\end{array}$ & Study case \\
\hline \multirow[b]{2}{*}{ I } & \multirow[b]{2}{*}{ Poorly graded sand SP (sand) } & \multirow[b]{2}{*}{93.6} & \multirow[b]{2}{*}{1.0} & 1510 & 39.6 & $5.1 \times 10^{-4}$ & Case I-A \\
\hline & & & & 1580 & 37.3 & $3.6 \times 10^{-4}$ & Case I-B \\
\hline \multirow{2}{*}{ II } & \multirow{2}{*}{ Silty sand SM (sandy loam) } & \multirow{2}{*}{67.0} & \multirow{2}{*}{0.4} & 1519 & 46.8 & $9.3 \times 10^{-6}$ & Case II-A \\
\hline & & & & 1650 & 42.2 & $6.8 \times 10^{-6}$ & Case II-B \\
\hline
\end{tabular}

The possibility of a center pivot irrigation system coupled with wireless sensors has been studied and found reasonable [12]. Remote sensing and contemporary information and communication techniques have been successfully applied to manage agricultural water demands and monitor soil responses [13]. Utilizing real-time soil moisture data from the fields and adopting a water balancing approach proved to be worthwhile in water conservation; however, the communication and software techniques for irrigation engineering such as the Internet of Things (IoT) need further improvement [14]. The cost of smart irrigation system installations is somewhat challenging for the local farmers, while the development and production are increasing. Most of the current studies focus on monitoring soil, climate, and water parameters [15].

Apart from digital technology, existing studies in soil and hydraulics also indicate better agriculture water management and crop yields. Subsurface irrigation or subsurface drip irrigation is one of these methods. The subsurface drip irrigation system claims to have better Alfalfa crop yield and water consumption in California [16]. Subsurface irrigation proved as a better option for cherry orchids in northern China when compared with conventional surface irrigation systems [17]. A study conducted on a subsurface pipe drainage drip irrigation system in Xinjiang, China, was effective for soil salinity control up to $2 \mathrm{~m}$ of depth [18]; however, more theoretical studies and experimental data are required to establish the fact.

Throughout the irrigation phases, the soil undergoes various wetting and drying cycles which change soil pressure and saturation conditions. The variation in pressure and water content is an inherent property of each soil type and can be presented by the soil water characteristic curve (SWCC). The saturated-unsaturated cycles affect the soil structure and long-term stability [19]. Smart irrigation technology enables to open up novel ideas in irrigation that were not workable before. With the help of electronic sensors, the water requirement at the target root zone can be precisely 


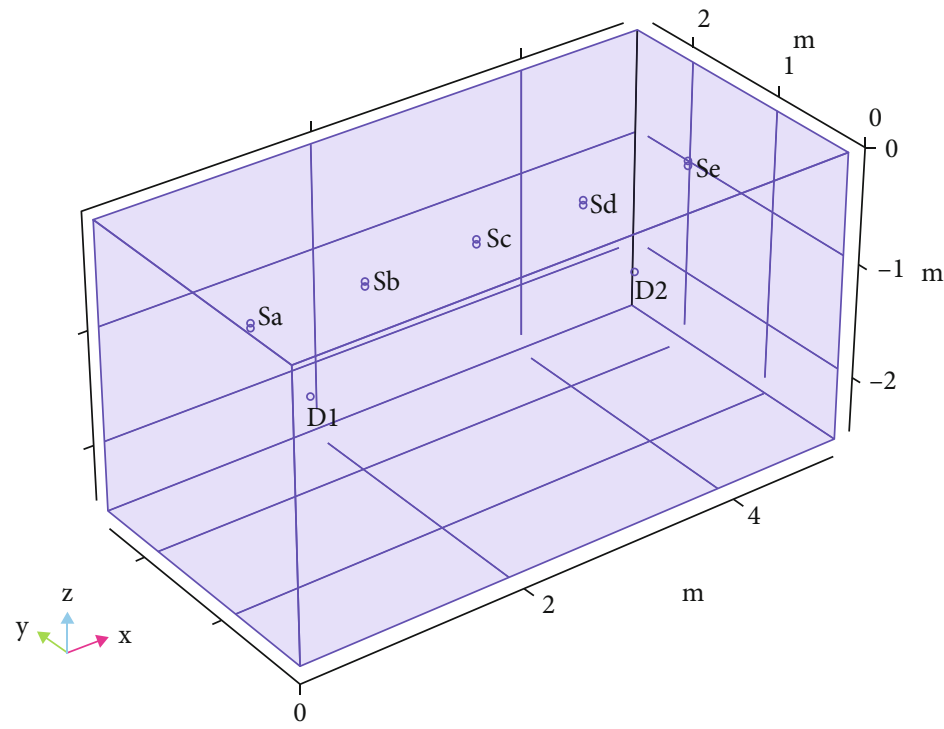

FIgURE 2: Subsurface smart irrigation system geometry with sensors and diffusers.

monitored, and extremes of SWCC can be avoided. Unfortunately, the laboratory determination of unsaturated soil behavior is uneconomical and time-consuming [20]. Therefore, a numerical approach has been adopted in this study to evaluate the possibility of a subsurface irrigation system for the arid sandy zones of the Middle East region. This research is aimed at developing a fully automated complete subsurface irrigation system. In the proposed irrigation system, the water will be supplied by the subsurface pipeline network with diffusers at desirable locations. The flow rate and diffuser's location shall be designed based on crop requirements, and the soil moisture sensors will be placed in the target root zone. These IoT-based sensors will send the wireless signals to terminate the irrigation supply once the desired saturation level is achieved. The irrigation resumes when soil saturation drops due to infiltration and evapotranspiration. The system incorporates the effect of local soil and climatic conditions and supplies the water as per crop requirement. The overall process avoids surface evaporation. The outcome of the study will not only help in water conservation but also advise public sector stakeholders in policymaking and social counselling.

\section{Materials and Method}

Madinah province is one of the vital agricultural zones of the kingdom of Saudi Arabia. The region is historically famous for its palm trees. In this study, two different soils from the $\mathrm{Al}$ Madinah area are selected. The soils mainly differ by their fine content. The grain size distribution curves for both the soils are shown in Figure 1. Soil-I is pure sand having a median particle diameter $\left(D_{50}\right)$ of about $1 \mathrm{~mm}$, whereas soil-II has reasonable fines with a particle diameter $\left(D_{50}\right)$ of $0.4 \mathrm{~mm}$. Soil gradation has been performed as per ASTM guidelines [21].

The engineering and agricultural soil classification for both soils and fundamental hydrogeologic properties deter-
TABle 2: Description and positioning of smart irrigation sensors.

\begin{tabular}{lccc}
\hline Sr. no & Device symbol & Description & Position $(x, y, z)$ \\
\hline 1 & Sa & Sensor-a & $(0.5,1.25,-0.5)$ \\
2 & D1 & Diffuser-1 & $(1.0,1.25,-1.25)$ \\
3 & Sb & Sensor-b & $(1.5,1.25,-0.5)$ \\
4 & Sc & Sensor-c & $(2.5,1.25,-0.5)$ \\
5 & Sd & Sensor-d & $(3.5,1.25,-0.5)$ \\
6 & D2 & Diffuser-2 & $(4.0,1.25,-1.25)$ \\
7 & Se & Sensor-e & $(4.5,1.25,-0.5)$ \\
\hline
\end{tabular}

TABLE 3: Soil parameters adopted for unsaturated flow models.

\begin{tabular}{|c|c|c|c|c|}
\hline $\begin{array}{l}\text { Test } \\
\text { case }\end{array}$ & Description & $\begin{array}{l}\text { Initial water } \\
\text { content, } \theta_{i} \\
(\%)\end{array}$ & $\begin{array}{c}\text { Initial } \\
\text { suction, } \psi_{i} \\
(\mathrm{kPa})\end{array}$ & $\begin{array}{c}\text { Saturated } \\
\text { water content, } \\
\theta_{s}(\%)\end{array}$ \\
\hline $\begin{array}{l}\text { Case } \\
\text { I-A }\end{array}$ & $\begin{array}{l}\text { Loose to } \\
\text { medium sand }\end{array}$ & 2 & 25 & 39.6 \\
\hline $\begin{array}{l}\text { Case } \\
\text { I-B }\end{array}$ & $\begin{array}{l}\text { Medium to } \\
\text { dense sand }\end{array}$ & 2 & 25 & 37.3 \\
\hline $\begin{array}{l}\text { Case } \\
\text { II-A }\end{array}$ & $\begin{array}{l}\text { Loose to } \\
\text { medium } \\
\text { sandy loam }\end{array}$ & 2 & 30 & 46.8 \\
\hline $\begin{array}{l}\text { Case } \\
\text { II-B }\end{array}$ & $\begin{array}{l}\text { Medium to } \\
\text { dense sandy } \\
\text { loam }\end{array}$ & 2 & 30 & 42.2 \\
\hline
\end{tabular}

mined in the laboratory are organized in Table 1. The soil classification has been done by using the unified soil classification system (USCS) [22] and the United States Department of Agriculture (USDA) classification [23]. The smart irrigation system has been simulated by using the subsurface flow module of the COMSOL Multiphysics program. The module has been successfully utilized by researchers for 
Model calibration by SWCCs of Edosaki sand

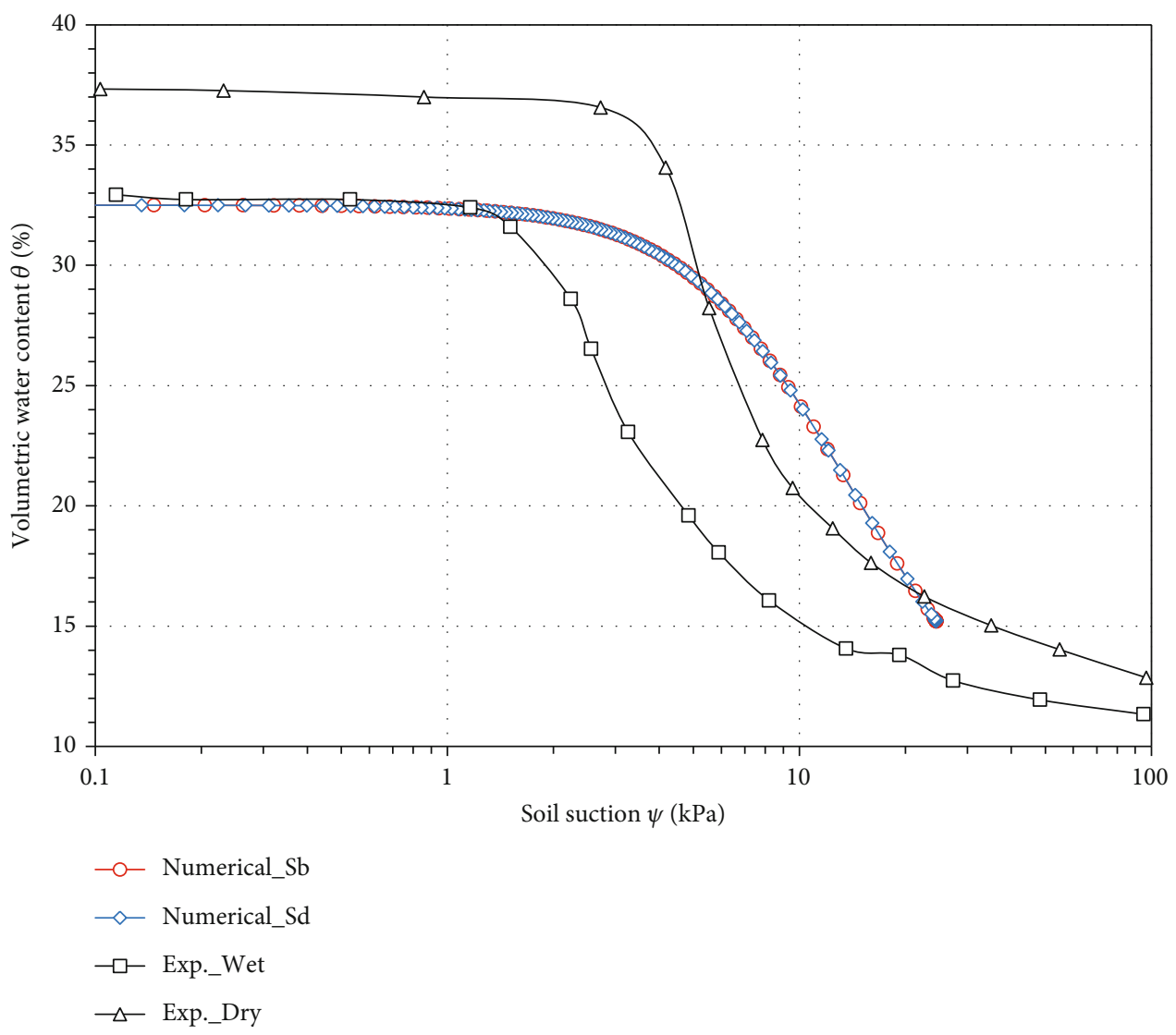

FiguRE 3: Model calibration by comparing SWCCs of Edosaki sand from experimental and simulation results.

various geomechanics problems $[24,25]$. In this analysis, a total of four (04) numerical cases based on soil properties were investigated by considering two different compaction levels of each soil type. The variation in soil porosity $(n)$ and coefficient of permeability $(k)$ concerning compaction levels (density) is also reflected in Table 1 . The porosity and hydraulic conductivity (coefficient of permeability) for all four cases were determined in the laboratory as per ASTM standards. The soil with more fines has less hydraulic conductivity and a high void ratio as compared to pure sand.

The finite element-based numerical model for the subsurface smart irrigation system has been presented by a box geometry. The model is $2.5 \mathrm{~m}$ deep and has a width of $2.5 \mathrm{~m}$ while its length is 5 meters. The axis orientation and the geometry of the FEM model are shown in Figure 2. Considering the average root depth of the date palm tree, the commercially most vital crop of the region, the soil moisture sensors are placed at a depth of $0.5 \mathrm{~m}$. The water supplying diffusers were placed at $1.25 \mathrm{~m}$ below the ground surface.

A total of five (05) soil moisture sensors placed $1 \mathrm{~m}$ apart are modeled. The system is irrigated by a couple of water diffusers; the distance between the diffusers is $3 \mathrm{~m}$. The detailed description and precise position of the soil moisture sensors and water supplying diffusers along with their adopted symbols are summarized in Table 2.

The irrigation diffusers are spherical in geometry with a diameter of $5 \mathrm{~cm}$; the diffusers are solid from the base and have a hemisphere opening at the top which acts as system inflow. The irrigation sensors are solid cylinders with a height of $5 \mathrm{~cm}$ and a diameter of $2.5 \mathrm{~cm}$. No flow conditions were applied across the sensors and bottom hemisphere of the diffusers. The top surface of the model is open to the atmosphere while the base and sides are permeable walls with the hydraulic conductivity same as that of the geomaterial. The gravitational forces are applied along the $z$-axis.

\section{Subsurface Flow Model}

The subsurface flow module of the COMSOL Multiphysics program can be applied to a variety of geoscience and engineering problems through fluid flow principles. Since the saturation conditions at the considered smart irrigation problem vary, in this study, Richards' equation principle for nonlinear flow in variably saturated porous media has been adopted [26]. The equation that governs the unsaturated flow in the soil mass can be written in the pressure head form as

$$
(C+\Theta S) \frac{\partial \psi}{\partial t}+\nabla \cdot[-k \nabla(\psi+D)]=0
$$

where $C$ is specific moisture capacity per meter, $\Theta$ is effective soil saturation, $S$ per meter is storage coefficient, $\psi$ is soil suction in meters, $t$ is time, $k$ is the coefficient of permeability, and $D$ is elevation. The Van Genuchten retention model has been 
Time $=30$ min Slice: effective saturation $(\Theta)(1) \quad$ Time $=100$ min Slice: effective saturation $(\Theta)(1)$

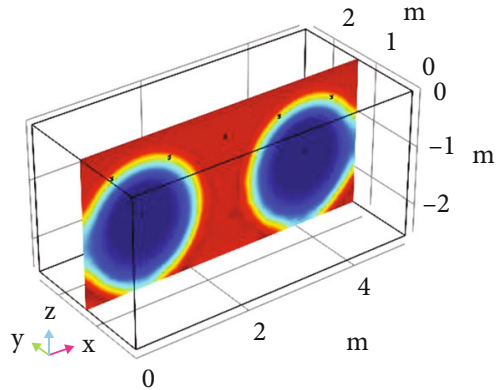

(a) 30 min irrigation
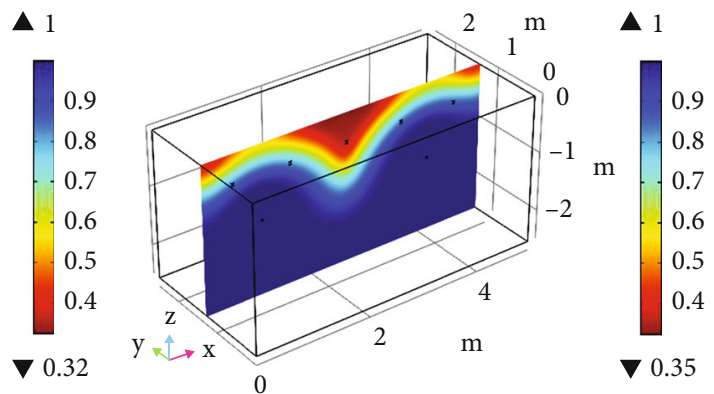

(b) 100 min irrigation

Time $=150$ min Contour: effective saturation (1)

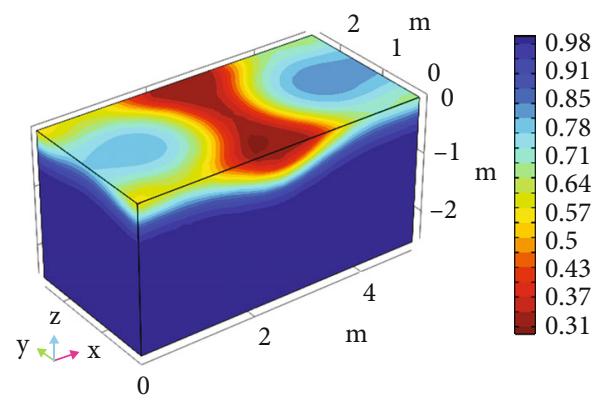

(c) 150 min irrigation

FIgURE 4: Effective saturation in the system for case I-A at different periods.

Time $=30$ min Slice: effective saturation $(\Theta)(1) \quad$ Time $=100$ min Slice: effective saturation $(\Theta)(1)$

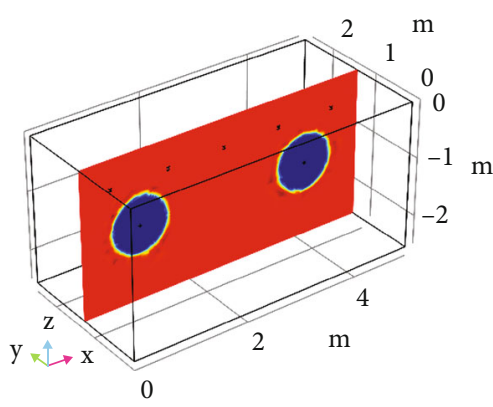

(a) 30 min irrigation

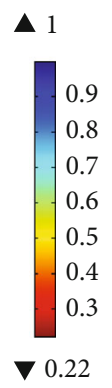

$\boldsymbol{\nabla} 0.22$

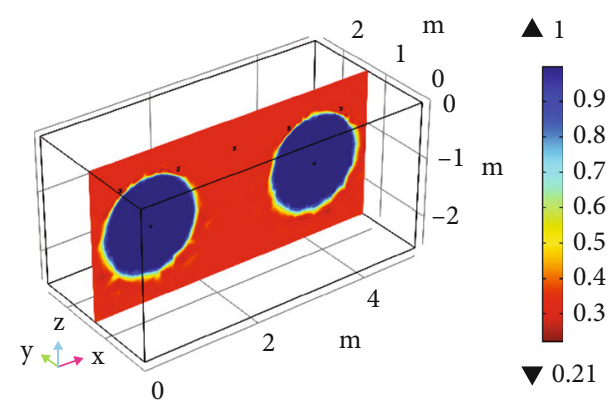

(b) 100 min irrigation

Time $=150$ min Slice: effective saturation $(\Theta)(1)$

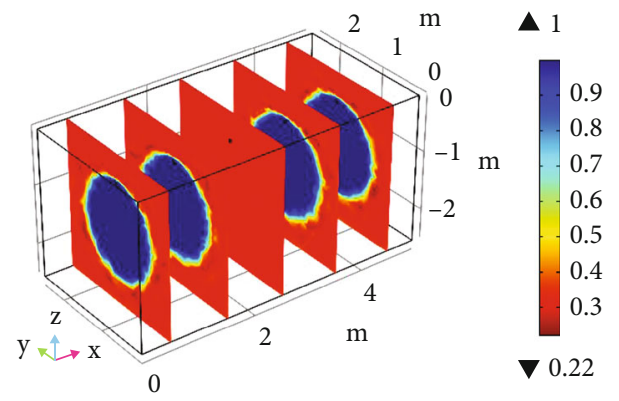

(c) 150 min irrigation

FiguRE 5: Effective saturation for case II-B at various time scales. 
Point graph: effective saturation $(\Theta)(\%)$

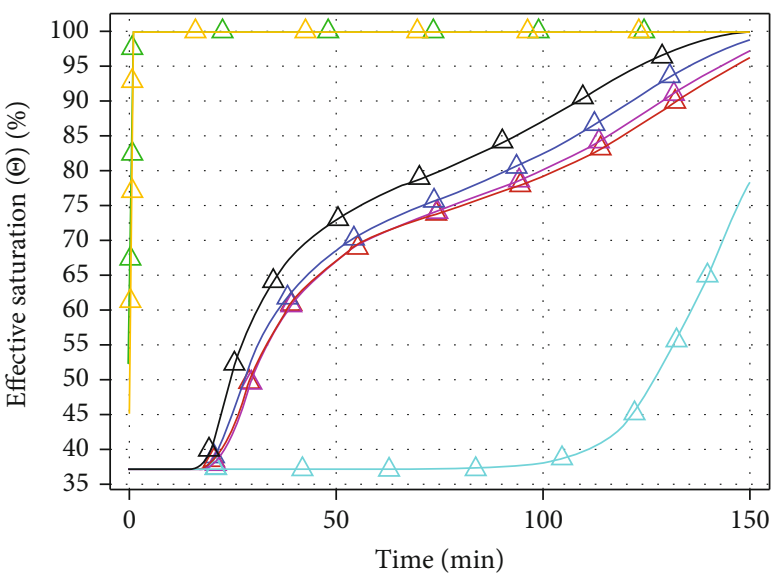

$$
\begin{array}{ll}
\triangle \mathrm{Sa} & \triangle \mathrm{Sd} \\
\triangle \mathrm{S} 1 & \triangle \mathrm{D} 2 \\
\triangle \mathrm{Sb} & \triangle \mathrm{Se} \\
\triangle \mathrm{Sc} &
\end{array}
$$

(a) Case I-A, medium sand

Point graph: effective saturation $(\Theta)(\%)$

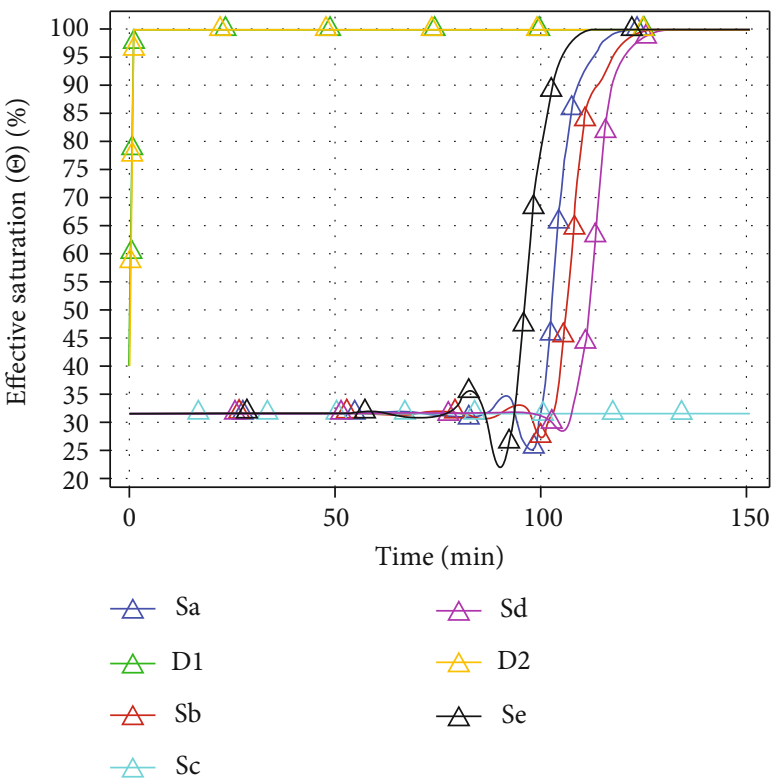

(c) Case II-A, medium sandy loam
Point graph: effective saturation $(\Theta)(\%)$

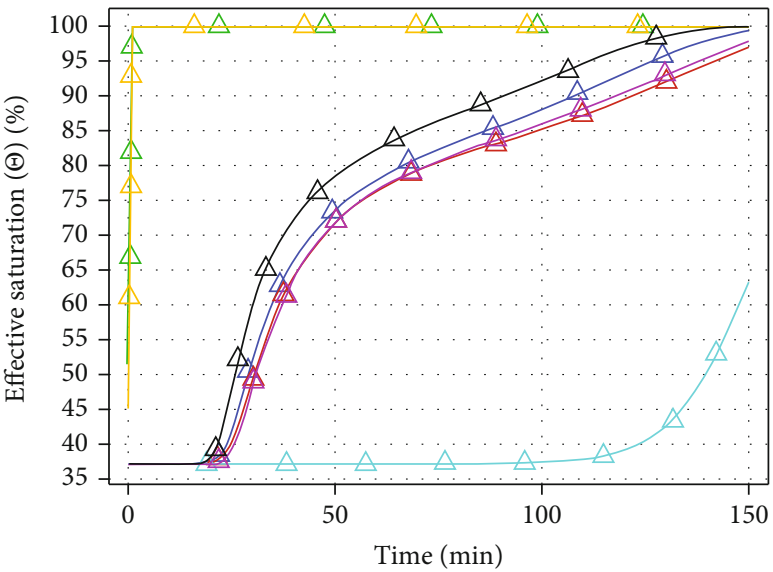

$$
\begin{array}{ll}
\triangle \mathrm{Sa} & \triangle \mathrm{Sd} \\
\triangle \mathrm{S} \text { D1 } & \triangle \mathrm{D} 2 \\
\triangle \mathrm{Sb} & \triangle \mathrm{Se} \\
\triangle \mathrm{Sc} &
\end{array}
$$

(b) Case I-B, dense sand

Point graph: effective saturation $(\Theta)(\%)$

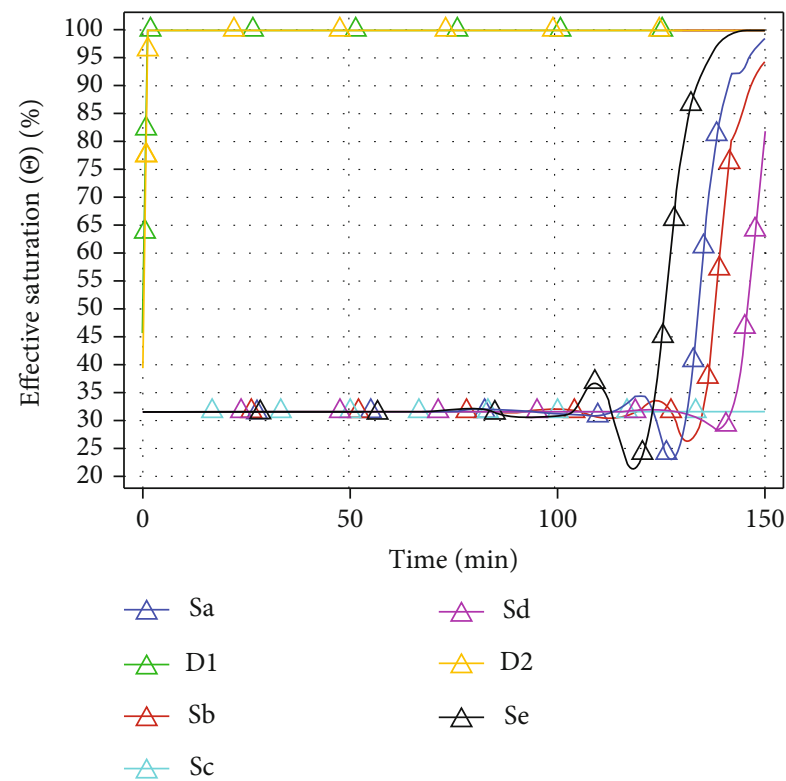

(d) Case II-B, dense sandy loam

FiguRE 6: Effective saturation history of four cases at inflow velocity of $1 \mathrm{~m} / \mathrm{s}$.

used to determine the saturation condition [27]. The van Genuchten equations define saturation when the fluid pressure is atmospheric (that is, $\psi=0$ ). These equations are

$$
\theta= \begin{cases}\theta_{i}+\Theta\left(\theta_{s}-\theta_{i}\right), & \psi<0 \text { (suction), } \\ \theta_{s}, & \psi \geq 0\left(p_{w}\right) .\end{cases}
$$

In Equation (2), $p_{w}$ is the pore water pressure and $\theta$ is the volumetric water content, while $\theta_{i}$ and $\theta_{s}$ are initial and satu- rated water contents. The effective saturation corresponding to the SWCC is based on

$$
\Theta= \begin{cases}\frac{1}{\left[1+|\alpha \psi|^{n}\right]^{m}}, & \psi<0 \text { (suction), } \\ 1, & \psi \geq 0\left(p_{w}\right),\end{cases}
$$

where $\alpha, n$, and $m$ are coefficients of SWCC. 
Time $=60 \min$ Slice: pressure $(\mathrm{kPa})$

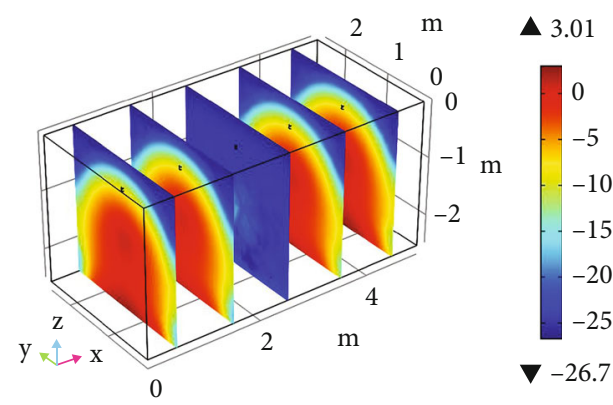

(a) Case I-A, medium sand
Time $=60$ min Slice: pressure $(\mathrm{kPa})$

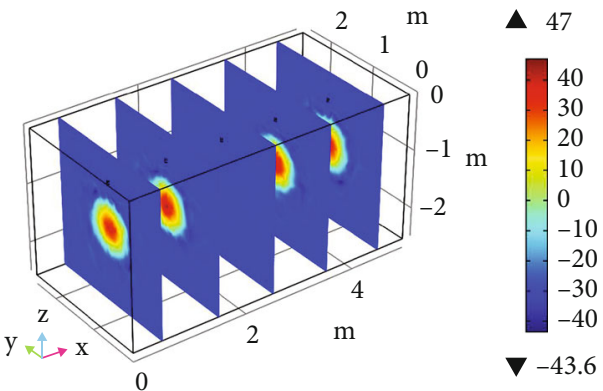

(b) Case II-B, dense sandy loam

FIgURE 7: Pressure distribution after $1 \mathrm{hr}$ of irrigation.

The specific moisture capacity $\left(C_{m}\right)$ of the system can be defined as follows:

$$
C= \begin{cases}\frac{\alpha m}{1-m}\left(\theta_{s}-\theta_{i}\right) \Theta^{1 / m}\left[1-\Theta^{1 / m}\right]^{m}, & \psi<0 \text { (suction), } \\ 0, & \psi \geq 0\left(p_{w}\right) .\end{cases}
$$

The hydraulic conductivity $(k)$ of the soil varies with the degree of saturation as a usual case the value of hydraulic conductivity is measured in the laboratory at fully saturated conditions. Therefore, the relative permeability value at partially saturated conditions is required to be used for accurate analysis. The permeability reduction factor $\left(k_{r}\right)$ is defined as

$$
k_{r}= \begin{cases}\Theta^{l}\left(1-\left[1-\Theta^{1 / m}\right]^{m}\right)^{2}, & \psi<0 \text { (suction) }, \\ 1, & \psi \geq 0\left(p_{w}\right) .\end{cases}
$$

In the above equation, " $l$ " is also a SWCC constant.

The time-based numerical analysis has been started with an almost dry state with a very low initial water content value, i.e., $2 \%$. The typical but rather conservative values of initial soil suction pressures were assumed for each soil type [28]. The saturated water content is taken as equivalent to the respective porosity. The soil parameters related to SWCC adopted in the numerical study for the four test cases are shown in Table 3.

3.1. Model Calibration. Since the SWCC is independent of flow rate and time, model calibration has been performed by comparing simulated and experimental soil water characteristic curves (SWCCs). The wetting and drying phases of the experimental SWCC are used from the literature obtained by Gallage and Uchimura for dense Edosaki sand [29]. The simulation-based SWCCs were generated by using the properties of Edosaki sand in a smart irrigation model. The internal sensor locations $\mathrm{Sb}$ and $\mathrm{Sd}$ were targeted for the SWCCs of numerical simulations. The calibration curves are shown in Figure 3. Most of the numerical values of SWCC are within the wetting and drying zones of the experimental data except for the 6 to $20 \mathrm{kPa}$ suction range. Since the smart irrigation model is primarily based on the saturation state, the numerical values well coincide with the wetting experimental curve at higher saturation. Considering natural variations in sands, it can be said that the model is quite consistent with the real soil behavior.

\section{Results and Discussions}

Soil saturation condition plays a very vital role in plant growth [30]; different crop roots have different saturation and void entrapped oxygen requirement for optimal growth. In this study, the effective saturation for the target root zone is numerically monitored by five sensors (Sa to Se). The irrigation is provided for 150 mins at the unit supply rate of $1 \mathrm{~m} / \mathrm{s}$. The saturation conditions for medium sand, i.e., for case I-A, are graphically shown in Figure 4. In Figure 4(a), the $2-\mathrm{D}$ cut plane in the $X-Z$ direction of the irrigation system is shown after 30 minutes of the irrigation cycle. The deep blue circular area around the diffusers represents the full saturation condition. At this stage, the effective saturation at the target root zone or the sensor's location is still less than $100 \%$. After 100 mins of irrigation (Figure 4(b)), more area becomes saturated; however, the area around sensor $\mathrm{Sc}$ which is at the farthest location from any of the diffusers is still in the dry zone. Most of the root zone (subsurface system) becomes fully saturated after 150 mins of irrigation of the 3-D saturation contour image of the system (Figure 4(c)) showing that the ground surface has different saturation levels.

The saturation history for case II-B (dense sandy loam) at the $1 \mathrm{~m} / \mathrm{s}$ irrigation rate is presented in Figure 5 . The saturation zone for dense sandy loam against each monitored time scale is quite smaller than that of the medium sand case. The irrigation effects did not reach any sensor after 30 mins of water supply (see Figure 5(a)). The saturation condition of the system after 100 and 150 mins, respectively, in $X-Z$ and $Y-Z$ directions can be seen in Figures 5(b) and 5(c).

The effective saturation history at the origin of all five sensors and both diffusers is presented in Figure 6. The sandy soil cases I-A and I-B are, respectively, shown in Figures 6(a) and 6(b), whereas the sandy loam cases II-A and II-B are shown in Figures 6(c) and 6(d). It can be seen 
Soil water characteristic curve

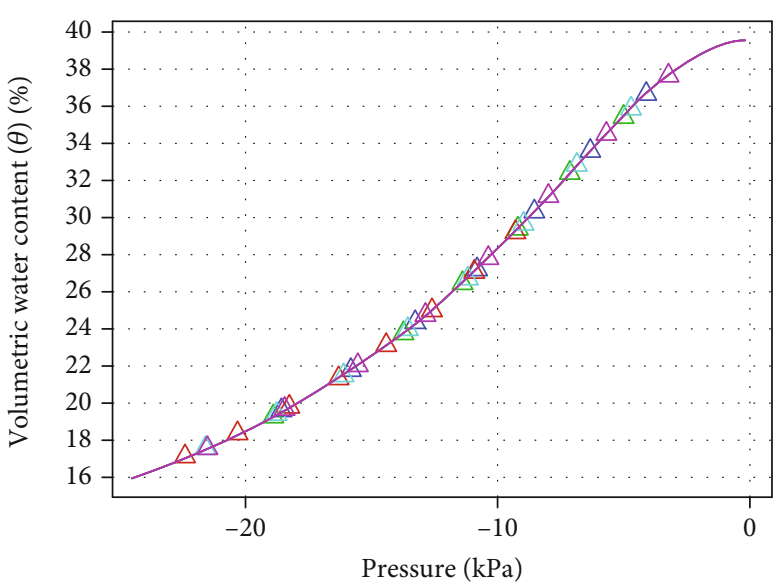
$\triangle \mathrm{Sa}$
$\triangle S d$
$\triangle \mathrm{Sb}$
$\triangle \mathrm{Se}$
$\triangle \mathrm{Sc}$

(a) Case I-A, medium sand
Soil water characteristic curve

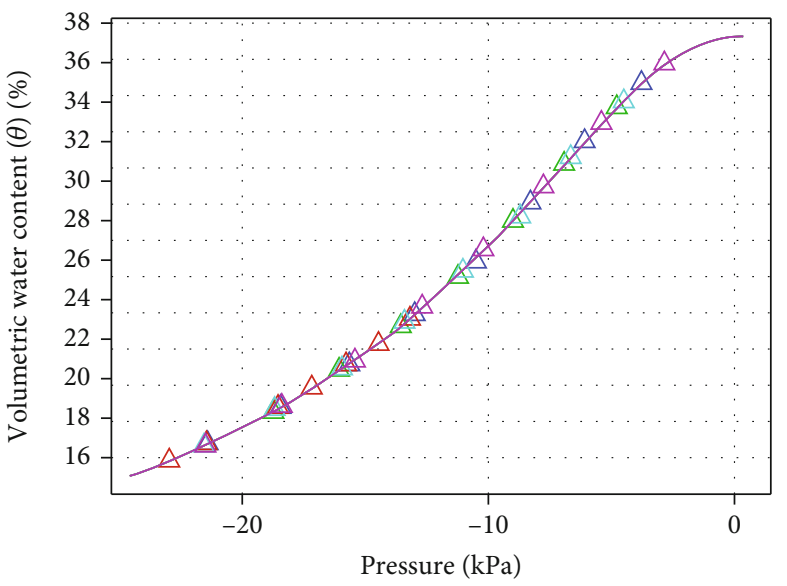
$\triangle \mathrm{Sa}$
$\triangle \mathrm{Sd}$
$\triangle \mathrm{Sb}$
$\triangle \mathrm{Se}$
$\triangle \mathrm{Sc}$

(b) Case I-B, dense sand

Soil water characteristic curve
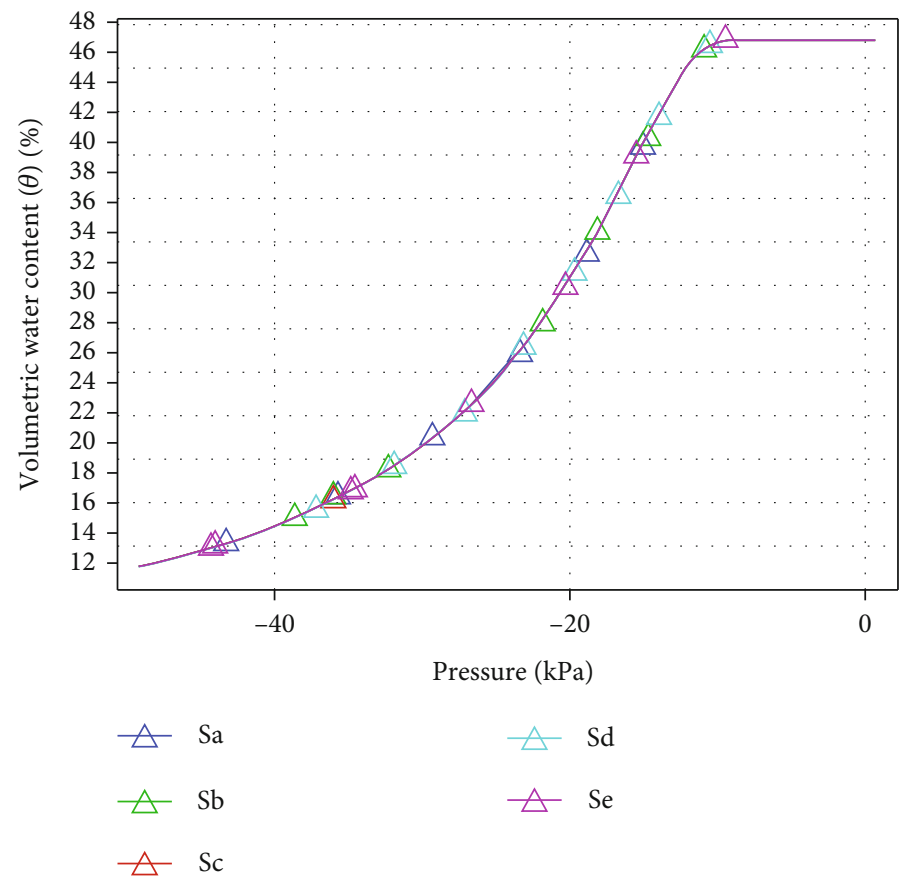

(c) Case II-A, medium sandy loam

Figure 8: Continued. 


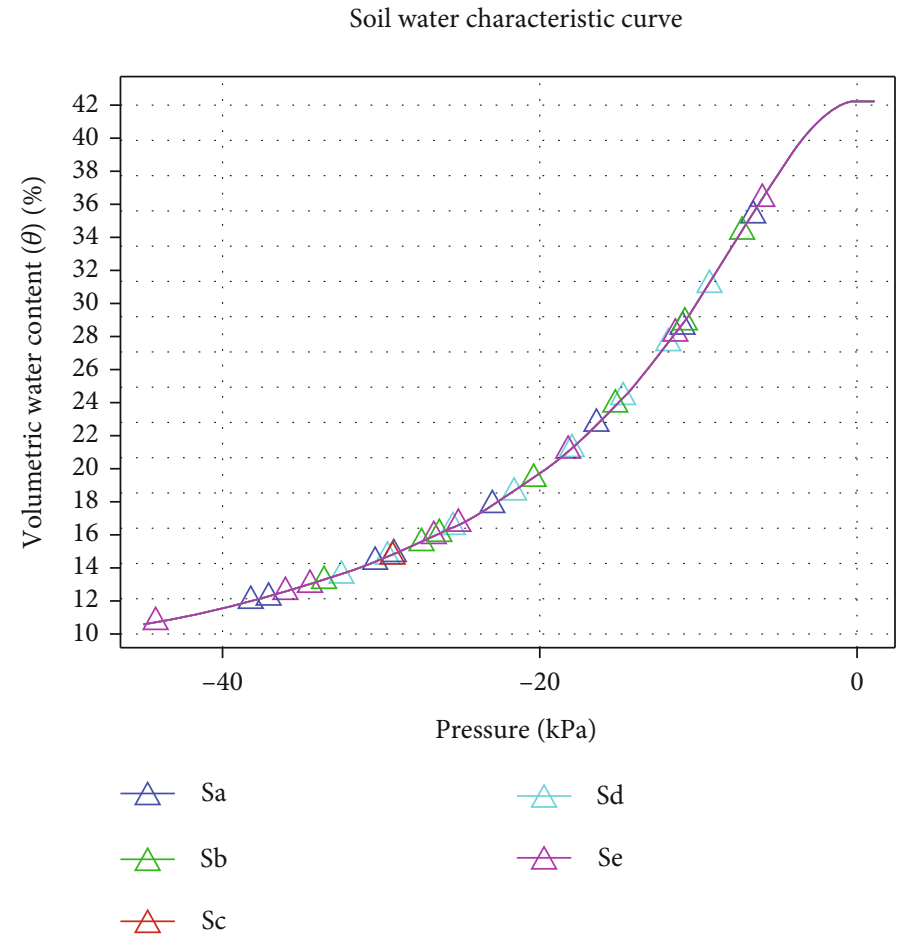

(d) Case II-B, dense sandy loam

FIgURE 8: Soil-water characteristic curves (SWCCs) of study cases at irrigation rate of $1 \mathrm{~m} / \mathrm{s}$.

Time $=150$ min Slice: effective saturation $(\Theta)(1)$

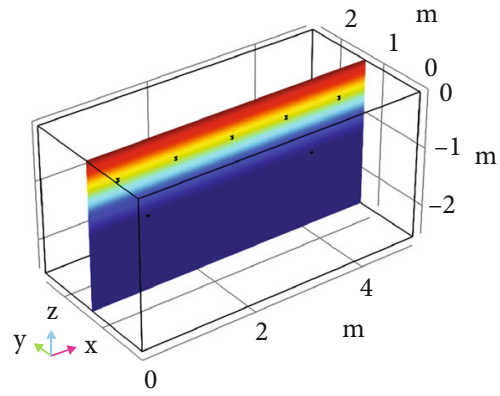

(a) Case I-A, medium sand

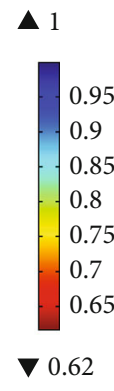

0.62 Time $=150$ min Slice: effective saturation $(\Theta)(1)$

FIgURE 9: Normalized water content after 150 mins of drying cycle.

from the figures that the medium-dense soils can be easily saturated as compared to their denser counterparts. The soil near the diffusers immediately gets saturated, while the farthest sensor Sc remains unsaturated for the entire irrigation duration. This implies that extra sensors may send inappropriate communication to the irrigation system and the irrigation may unnecessarily continue for a longer period. The saturation extent in loamy sand takes more time; nevertheless, their saturation history curves are steeper than that of sandy soils. This is due to the low infiltration rate in fine soils, and water can only be transmitted to the next voids after complete saturation. Based on the crop requirements, an optimal balance between entrapped air and water content is necessary for the soil system. The smart irrigation system can be easily programmed for the duration of irrigation by utilizing the input from the moisture sensors.

One of the concerns in a subsurface irrigation system is the development of pore water pressure. The unsaturated soil naturally has suction pressure which plays a role in the structural stability of the soil, as the soil gets saturated it loses suction, and water infiltration beyond full saturation can lead to the development of porewater pressure. The pore water pressure development in the system after 60 minutes of irrigation at a unit flow rate for the two distinct cases, i.e., medium sandy soil and dense sandy loam, is shown in Figure 7. The sandy soil (Figure 7(a)) has lost a sufficient amount of suction in the system, and a very minute pore water pressure developed near diffusers. The compacted 
Point graph: effective saturation $(\Theta)(\%)$

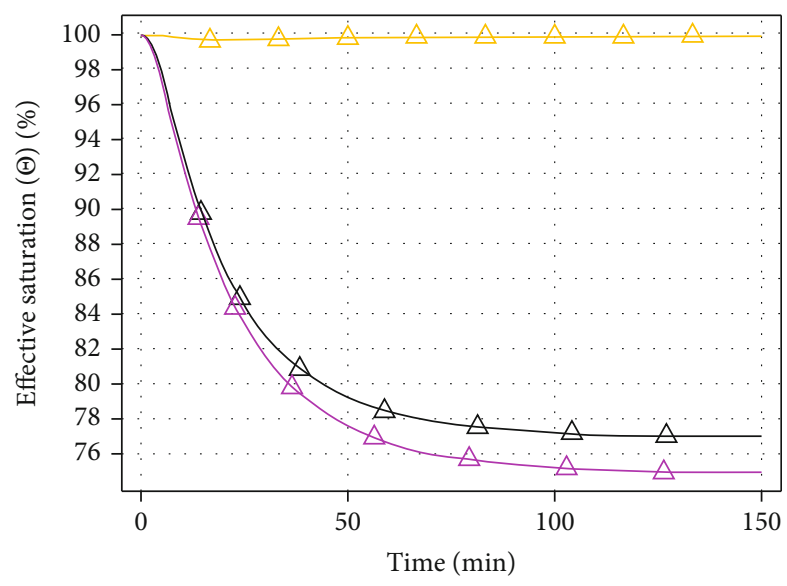

(a) Case I-A, medium sand

Point graph: effective saturation $(\Theta)(\%)$

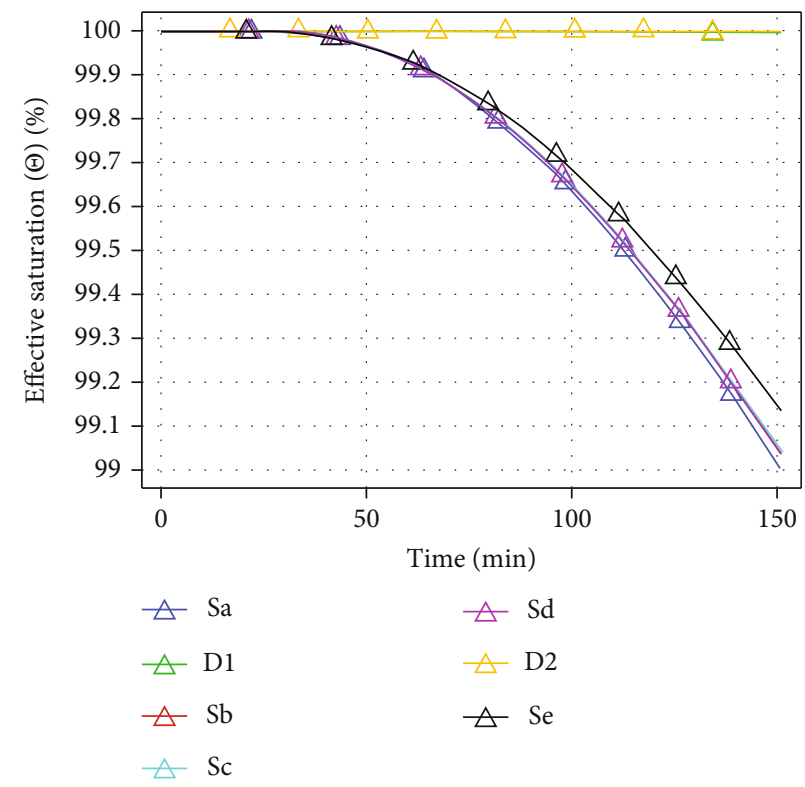

(c) Case II-B, medium sandy loam

Point graph: effective saturation $(\Theta)(\%)$

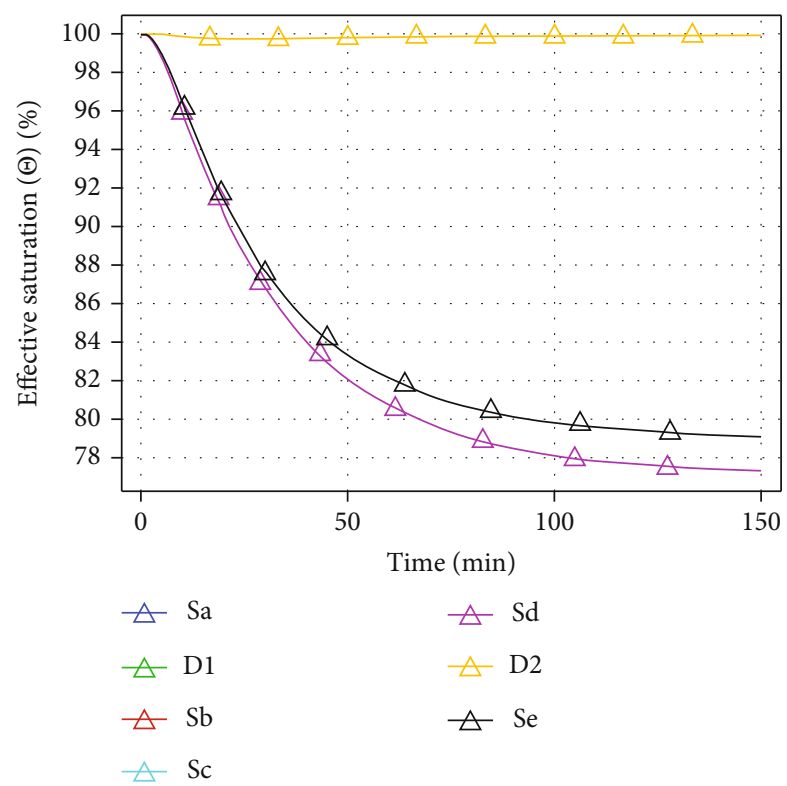

(b) Case I-A, dense sand

Point graph: effective saturation $(\Theta)(\%)$

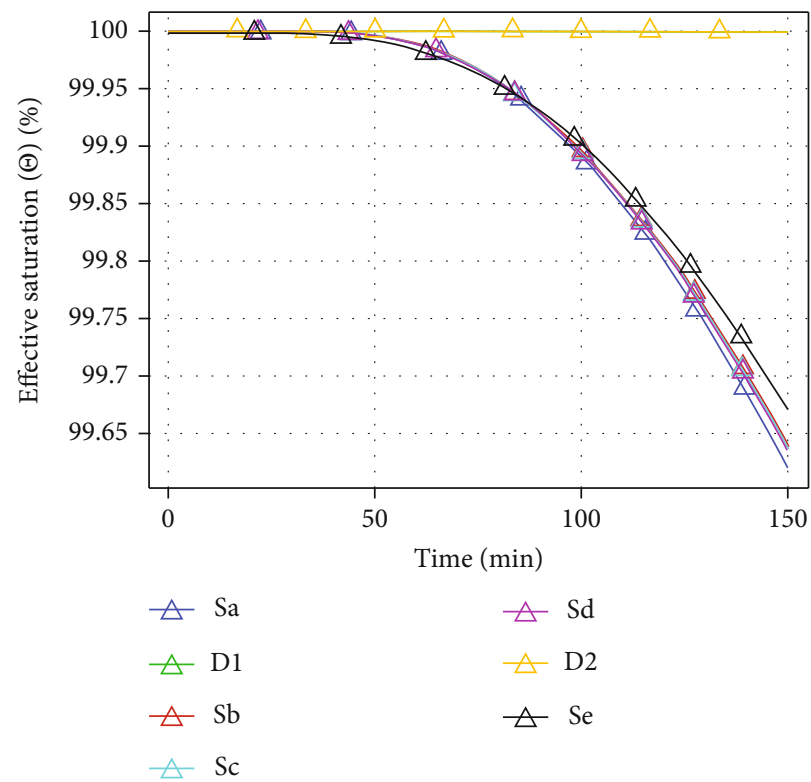

(d) Case II-B, dense sandy loam

FIgURe 10: Postirrigation retention history for all soil cases.

sandy loam (Figure 7(b)) has a large unsaturated area with a high suction value as well as high pore pressure accumulation (up to $47 \mathrm{kPa}$ ) near diffusers.

The portion of the SWCC up to full saturation for the four study cases at an irrigation rate of $1 \mathrm{~m} / \mathrm{s}$ is shown in Figure 8. The SWCC at the target sensor's location has a similar pattern for each soil type while the saturation range is different. This can be seen by comparing medium and dense soil cases of the same soil type, i.e., Figure 8(a), with Figures 8(b)-8(d).
4.1. Postirrigation Retention. One of the key objectives of the complete subsurface irrigation system is to minimize surface evaporation, this will enhance the postirrigation retention, and the only water loss is due to the gravitational infiltration. After the completion of the irrigation cycle, the water will distribute in the system, in an ideal situation the whole system becomes fully saturated, and the water supply cuts off. The fully saturated system is monitored for water loss due to infiltration for 150 mins. The normalized water content for medium sand and sandy loam cases can be compared 


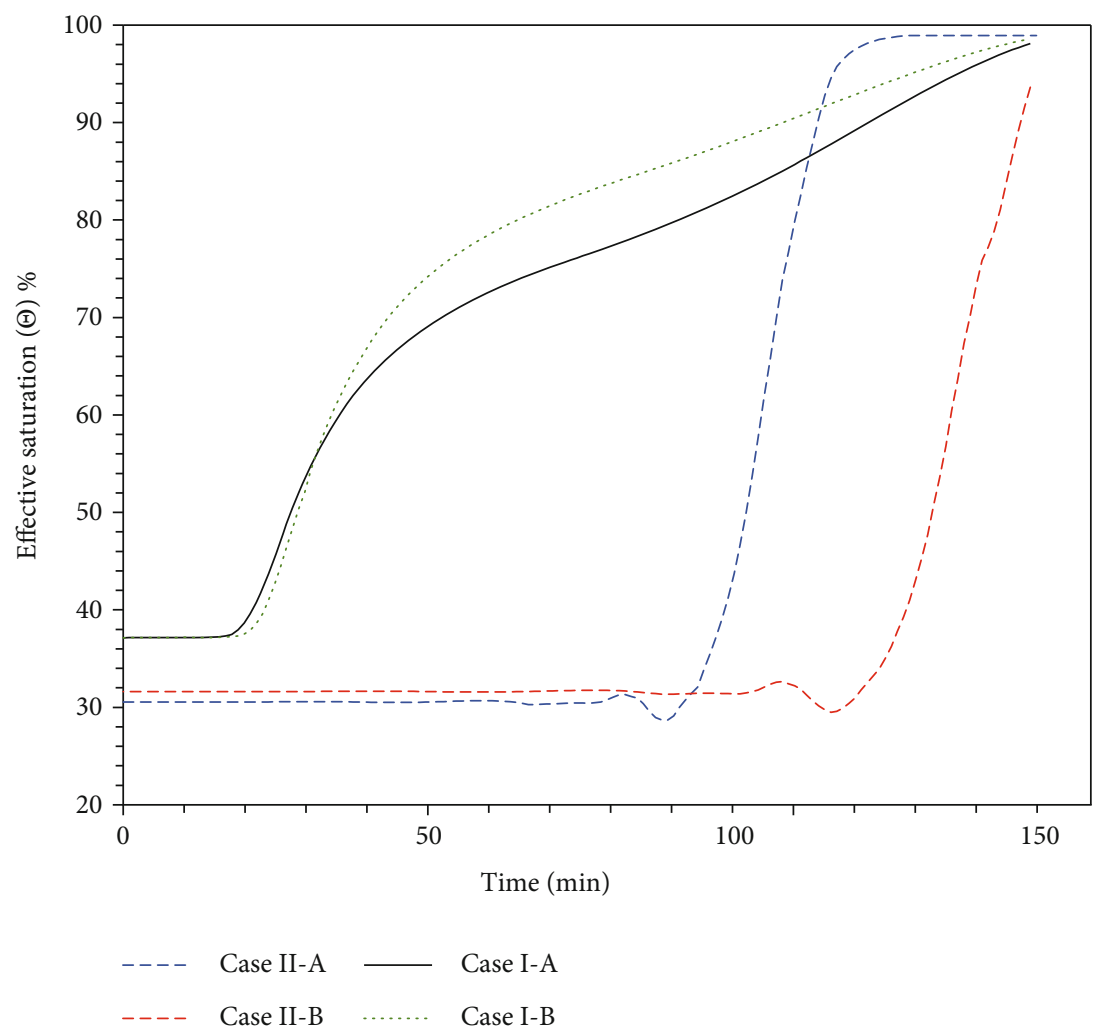

FIGURE 11: Saturation history of studied cases at unit irrigation rate.

from Figures 9(a) and 9(b). The sandy soil system has lost around $30 \%$ of saturation near the target root zone or at sensor locations and around $40 \%$ on the surface, while the sandy loam system is almost saturated and lost only $6 \%$ of saturation near the surface.

The postirrigation retention is further elaborated by plotting the $150 \mathrm{~min}$ history at the target sensor's location for all four cases (Figure 10). In sandy soil cases shown in Figures $10(\mathrm{a})$ and $10(\mathrm{~b})$, the effective saturation $(\Theta)$ drops up to $77 \%$ with a marginal difference between the exterior ( $\mathrm{Sa}$ and $\mathrm{Se}$ ) and internal (Sb, Sc, and $\mathrm{Sd}$ ) monitoring locations. The soil with fine content performs remarkably well in terms of retention, and only a $1 \%$ drop in effective saturation $(\Theta)$ is observed (Figures $10(\mathrm{c})$ and $10(\mathrm{~d})$ ).

\section{Further Discussions}

The summary of effective saturation $(\Theta)$ history for all four cases at an irrigation rate of $1 \mathrm{~m} / \mathrm{s}$ is illustrated in Figure 11. The graph presents the average data of the two inner soil moisture sensors $\mathrm{Sb}$ and $\mathrm{Sd}$ since they are least affected by boundary conditions. The irrigation water quickly reaches the target location in sandy soils due to their higher permeability, while it takes more than one hour for sandy loam. The sandy soils transmit water to the adjacent locations before achieving full saturation, their saturation history curves are flatter, and they eventually take more time to achieve full saturation. On the other hand, medium sandy loam has a very steep saturation history curve, and once the saturation starts, it quickly achieves full saturation. The saturation history curve of the dense sandy loam (case IIB) though has a similar slope as that of case II-A, but its overall duration is longer.

The flow rate plays a very vital role in irrigation systems for managing water availability, economy, and energy resources. The effect of the flow rate on peak saturation time for each of the study cases is illustrated in Figure 12. At the unit flow rate, medium sandy loam was the quickest to attain full saturation. While the dense sand (case I-B) takes the longest time. As the flow rate increases, peak saturation time for each material decreases quadratically with different ratios until the flow rate doubles; beyond $2 \mathrm{~m} / \mathrm{s}$ further decrease is almost linear. The sandy soils were easily affected by the flow rate as compared to the sandy loams.

As discussed earlier, the pore water pressure can easily build up in the subsurface irrigation systems; the effect of the flow rate on pw development is critical to evaluate for the system integrity. The effect of the flow rate on the maximum value of pore water pressure developed in the irrigation system is graphically presented in Figure 13. The pw increases linearly with an increase in the flow rate. The sandy soils (cases IA and IB) are less vulnerable to the pw development while sandy loams are greatly affected. Since the irrigation diffusers are expected to be placed at shallow depths, the net overburden stress to counter high pw will not be available and local soil failure followed by piping is likely to occur. Therefore, higher flow rates are impractical to apply.

In a subsurface irrigation system, the drying phase mainly depends on the water loss from gravitational infiltration; in this context, the top surface will be most affected. 


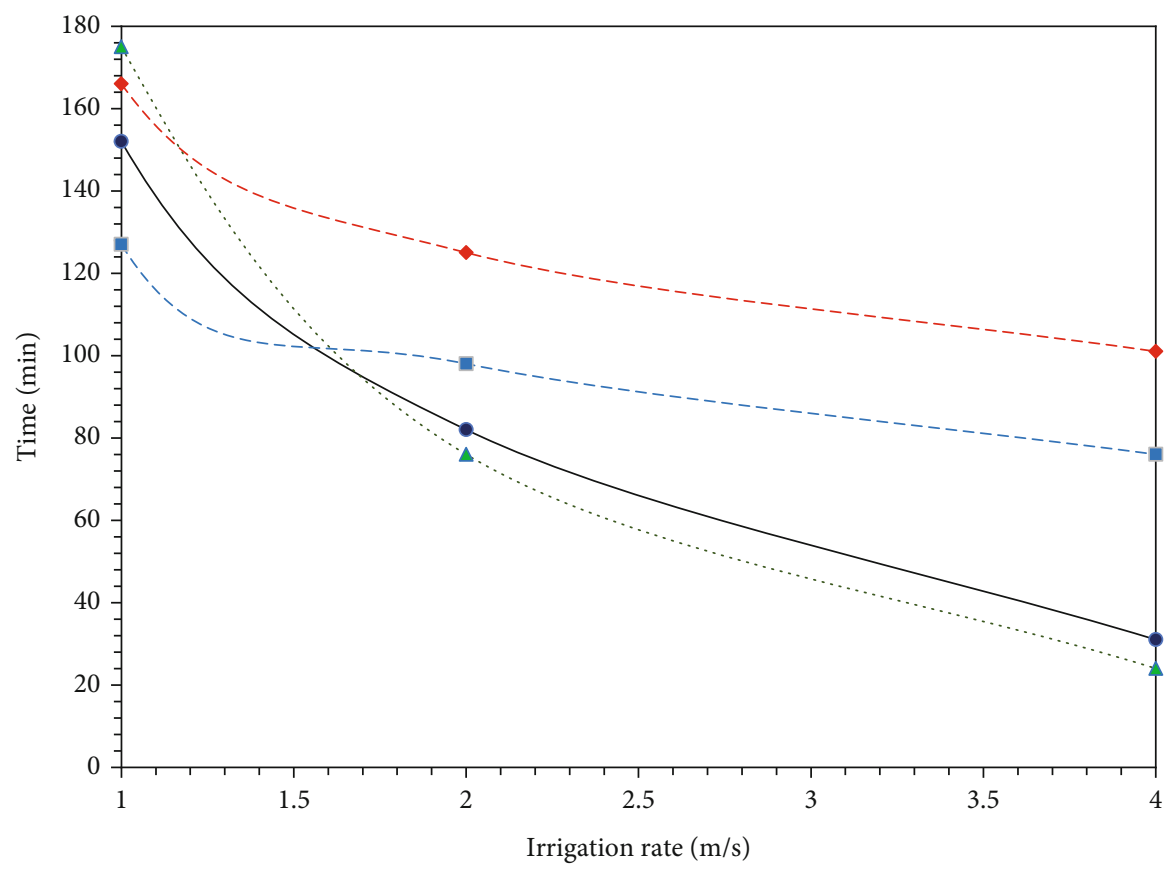

$\longrightarrow$ Case I-A $\quad----\quad$ Case II-A

$\cdots \cdots \quad$ Case I-B $\quad-\rightarrow-\quad$ Case II-B

FIgURE 12: Time required to attain full saturation vs. irrigation rate.

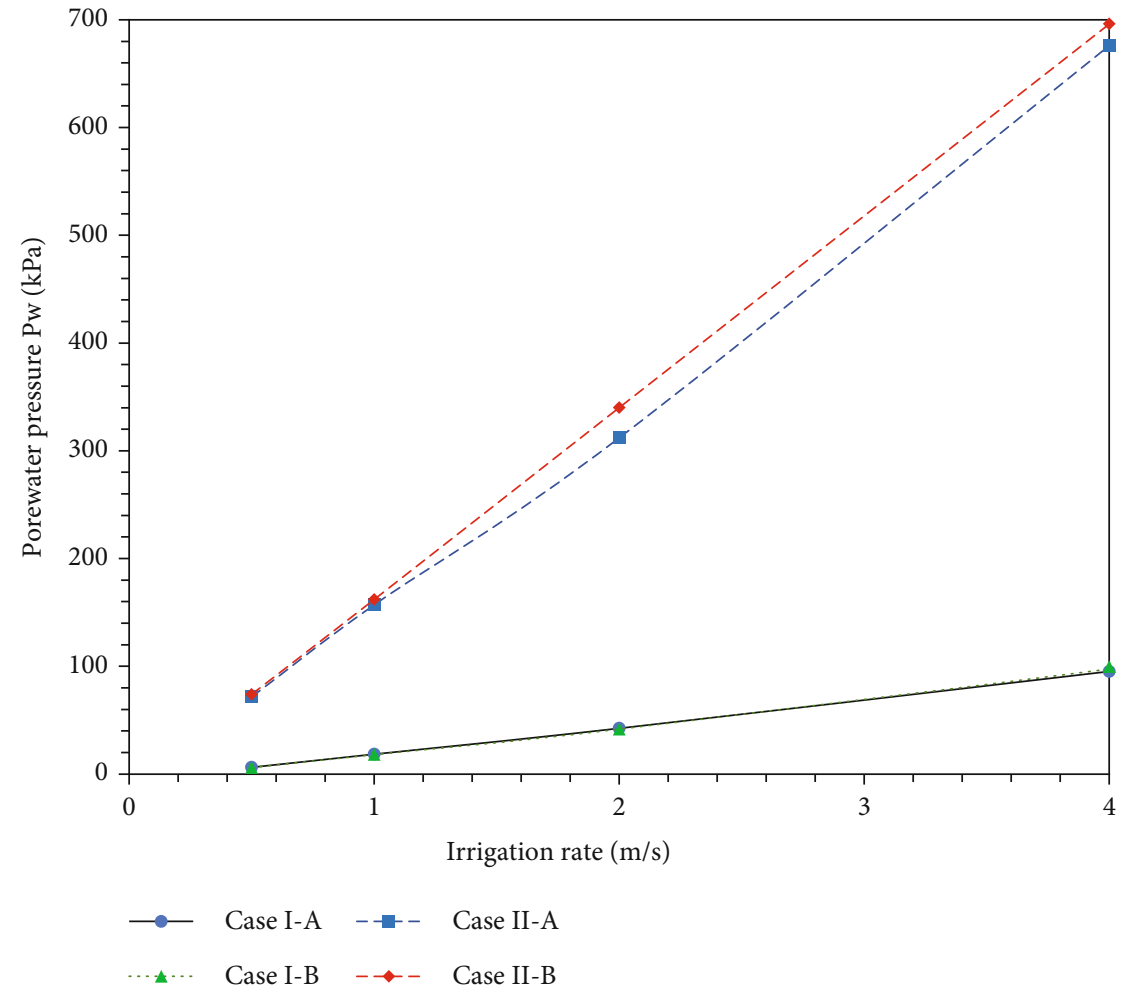

FIgURE 13: Peak porewater pressure (pw) in the system.

The loss in saturation at the surface after 150 minutes of the drying cycle for each study case is summarized in Figure 14. The sandy soils lost up to $38 \%$ normalized water content, while the soils having fines are well saturated. The dense soils have a better ability to hold water for a longer period due to their smaller pore size and better adhesion. 


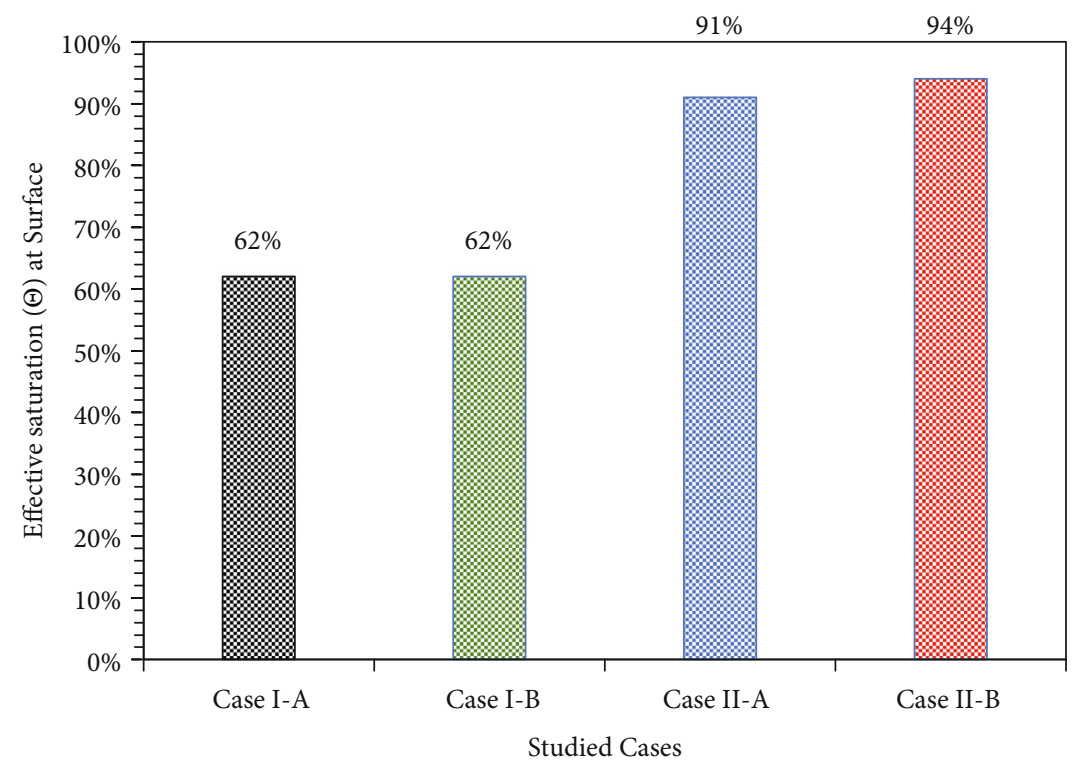

Figure 14: Normalized water content $(\theta)$ at the surface (150 min drying phase).

\section{Conclusions}

The FEM base flow analysis recognizes the possibility of a complete subsurface smart irrigation system with the help of contemporary digital techniques. The IoT soil moisture sensor should be intelligently planned within the root zone; improper placement of sensors may retain the irrigation supply for an excessive duration and impacts system sustainability.

The influence zone of irrigation diffusers depends on soil type and compaction characteristics. Soils with moderate compaction and up to $20 \%$ fine content proved reasonable for the subsurface irrigation systems. Sandy soils have inadequate water retention capabilities and can transmit water to the surroundings at medium saturation levels.

The subsurface systems should be irrigated at low to moderate flow rates. The high flow rate can generate an excess pore water pressure, and the soil's structural integrity will be compromised. In this context, IoT-based pore water pressure sensors must also be installed at critical locations.

The system is proposed for the permanent crops of the Arabian Peninsula, such as palms and olives. In the case of perennial crops, the sensors and diffusers shall be placed well below the plowing area. The experimental validation of the presented study, reliability of IoT devices, and communication system are the relevant prospective research topics.

\section{Data Availability}

The laboratory test results, figures, and tables used to support the findings of this study are included within the article.

\section{Conflicts of Interest}

The authors declare no conflict of interest.

\section{Acknowledgments}

The authors extend their appreciation to the Deputyship for Research \& Innovation, Ministry of Education - Kingdom of Saudi Arabia, for funding this research work through the project number (20/9).

\section{References}

[1] A. S. Alsharhan, Z. A. Rizk, A. E. Nairn, D. W. Bakhit, and S. A. Alhajari, "Hydrogeology of an arid region: the Arabian Gulf and adjoining areas," American Water Works Association. Journal, vol. 95, no. 5, p. 200, 2001.

[2] Q. U. Farooq and M. T. Naqash, "Performance of shallow building foundations under infrequent rainfall patterns at $\mathrm{Al}-$ Madinah, Saudi Arabia," The Open Civil Engineering Journal, vol. 15, no. 1, pp. 91-103, 2021.

[3] H. Hasanean and M. Almazroui, "Rainfall: features and variations over Saudi Arabia, a review," Climate, vol. 3, no. 3, pp. 578-626, 2015.

[4] "List of countries by GDP sector composition," p. 2021, 2018, https://statisticstimes.com/economy/countries-by-gdp-sectorcomposition.php.

[5] J. Bridge, R. Demicco, J. Bridge, and R. Demicco, "Arid environments," Earth Surface Processes, Landforms and Sediment Deposits, Cambridge University Press, 2012.

[6] S. S. Gabr, E. F. Farg, T. M. Habeebullah, and S. M. Arafat, "Irrigation water consumption and its impact on the groundwater aquifer of Wadi Uranah, Makkah, Saudi Arabia using remote sensing techniques," Egyptian Journal of Remote Sensing and Space Science, vol. 23, no. 2, pp. 167-180, 2020.

[7] A. A. Al-Ibrahim, "Excessive use of groundwater resources in Saudi Arabia: impacts and policy options," Ambio, vol. 20, 1991.

[8] O. A. Fallatah, "Groundwater quality patterns and spatiotemporal change in depletion in the regions of the Arabian shield 
and Arabian shelf," Arabian Journal for Science and Engineering, vol. 45, no. 1, pp. 341-350, 2020.

[9] S. Chowdhury and M. Al-Zahrani, "Characterizing water resources and trends of sector wise water consumptions in Saudi Arabia," Journal of King Saud University-Engineering Sciences, vol. 27, no. 1, pp. 68-82, 2015.

[10] J. Keller and R. D. Bliesner, Sprinkle and Trickle Irrigation, Van Nostrand Reinhold, New York, USA, 1990.

[11] V. C. Patil, K. A. Al-Gaadi, R. Madugundu et al., "Assessing agricultural water productivity in desert farming system of Saudi Arabia," IEEE Journal of Selected Topics in Applied Earth Observations and Remote Sensing, vol. 8, no. 1, pp. 284-297, 2015.

[12] X. Dong, M. C. Vuran, and S. Irmak, "Autonomous precision agriculture through integration of wireless underground sensor networks with center pivot irrigation systems," Ad Hoc Networks, vol. 11, no. 7, pp. 1975-1987, 2013.

[13] D. Masseroni, G. Arbat, and I. P. de Lima, "Editorial-managing and planning water resources for irrigation: smartirrigation systems for providing sustainable agriculture and maintaining ecosystem services," Water, vol. 12, no. 1 , p. 263, 2020.

[14] N. G. S. Campos, A. R. Rocha, R. Gondim, T. L. Coelho da Silva, and D. G. Gomes, "Smart \& amp; green: an internetof-things framework for smart irrigation," Sensors, vol. 20, no. 1, p. 190, 2019.

[15] L. García, L. Parra, J. M. Jimenez, J. Lloret, and P. Lorenz, "IoT-based smart irrigation systems: an overview on the recent trends on sensors and IoT systems for irrigation in precision agriculture," Sensors, vol. 20, no. 4, p. 1042, 2020.

[16] D. Zaccaria, M. T. Carrillo-Cobo, A. Montazar, D. Putnam, and K. Bali, "Assessing the viability of sub-surface drip irrigation for resource-efficient alfalfa production in central and southern California," Water, vol. 9, no. 11, p. 837, 2017.

[17] G. Peng, W. Bing, and Z. Guangcan, "Influence of sub-surface irrigation on soil conditions and water irrigation efficiency in a cherry orchard in a hilly semi-arid area of northern China," PLoS One, vol. 8, no. 9, article e73570, 2013.

[18] T. Heng, R. Liao, Z. Wang, W. Wu, W. Li, and J. Zhang, "Effects of combined drip irrigation and sub-surface pipe drainage on water and salt transport of saline-alkali soil in Xinjiang, China," Journal of Arid Land, vol. 10, no. 6, pp. 932-945, 2018.

[19] T. P. Tran and D. G. Fredlund, "Verification of the Fredlund (2019) unsaturated shear strength function," Geosciences, vol. 11, no. 4, p. 151, 2021.

[20] D. G. Fredlund and M. D. Fredlund, "Application of 'estimation procedures' in unsaturated soil mechanics," Geosciences, vol. 10, no. 9, p. 364, 2020.

[21] ASTM International, D6913: Standard Test Methods for Particle-Size Distribution (Gradation) of Soils Using Sieve Analysis, ASTM International, 2017.

[22] ASTM D2487-17, Standard Practice for Classification of Soils for Engineering Purposes (Unified Soil Classification System), ASTM International, West Conshohocken, PA USA, 2017, http://www.astm.org.

[23] P. Hughes, A. B. McBratney, B. Minasny et al., "Comparisons between USDA soil taxonomy and the Australian soil classification system II: comparison of order, suborder and great group taxa," Geoderma, vol. 322, pp. 48-55, 2018.
[24] T. Fong, M. Chui, and D. L. Freyberg, "The use of COMSOL for integrated hydrological modeling," in Proceedings of the COMSOL Conference 2007, pp. 217-223, Boston, 2007.

[25] O. Harireche, M. T. Naqash, and Q. U. Farooq, "A full numerical model for the installation analysis of suction caissons in sand," Ocean Engineering, vol. 234, article 109173, 2020.

[26] C. Multiphysics, "Subsurface Flow Module User's Guide," COMSOL Multiphysics Chapter 3, vol. 5, pp. 153-157, 2018.

[27] M. T. van Genuchten, "A closed-form equation for predicting the hydraulic conductivity of unsaturated soils," Soil Science Society of America Journal, vol. 44, no. 5, pp. 892-898, 1980.

[28] Z. F. Zhang, "Soil water retention and relative permeability for conditions from oven-dry to full saturation," Vadose Zone Journal, vol. 10, no. 4, pp. 1299-1308, 2011.

[29] C. P. K. Gallage and T. Uchimura, "Effects of dry density and grain size distribution on soil-water characteristic curves of sandy soils," Soils and Foundations, vol. 50, no. 1, pp. 161172, 2010.

[30] J. R. Schneider, A. Caverzan, and G. Chavarria, "Water deficit stress, ROS involvement, and plant performance," Archives of Agronomy and Soil Science, vol. 65, no. 8, pp. 1160-1181, 2019. 